Corresponding author: p.rosenstiel@mucosa.de

(c) 2019 Lipinski et al. This article is distributed under the terms of the Creative Commons Attribution-NonCommercial License, which permits reuse and redistribution, except for commercial purposes, provided that the original author and source are credited.

Ontology term: inflammation of the large intestine

Published by Cold Spring Harbor Laboratory Press

doi:10.1101/mcs.a002428

\section{Missense variants in NOX1 and p22phox in a case of very-early-onset inflammatory bowel disease are functionally linked to NOD2}

\begin{abstract}
Simone Lipinski, ${ }^{1,11}$ Britt-Sabina Petersen, ${ }^{1,11}$ Matthias Barann, ${ }^{1,11,12}$ Agnes Piecyk, ${ }^{1,9}$ Florian Tran, ${ }^{1,2}$ Gabriele Mayr, ${ }^{1}$ Marlene Jentzsch, ${ }^{1}$ Konrad Aden, ${ }^{1,2}$ Stephanie T. Stengel, ${ }^{1}$ Ulrich C. Klostermeier, ${ }^{1}$ Vrunda Sheth, ${ }^{3}$ David Ellinghaus, ${ }_{1}^{1}$ Tobias Rausch, ${ }^{4}$ Jan O. Korbel, ${ }^{4}$ Michael Nothnagel, ${ }^{5,10}$ Michael Krawczak, ${ }^{5}$ Christian Gilissen, ${ }^{6}$ Joris A. Veltman, ${ }^{6,7}$ Michael Forster, ${ }^{1}$ Peter Forster, ${ }^{8}$ Clarence C. Lee, ${ }^{2}$ Annette Fritscher-Ravens, ${ }^{2}$ Stefan Schreiber, ${ }^{1,2,11,12}$ Andre Franke, ${ }^{1,11}$ and Philip Rosenstiel ${ }^{1,11,12}$

${ }^{1}$ Institute of Clinical Molecular Biology (IKMB), Christian-Albrechts-University, 24105 Kiel, Germany; ${ }^{2}$ Department of General Internal Medicine, Christian-Albrechts-University, University Hospital SchleswigHolstein, 24105 Kiel, Germany; ${ }^{3}$ Life Technologies, Beverly, Massachusetts 01915, USA; ${ }^{4}$ European Molecular Biology Laboratory (EMBL), Genome Biology Unit, 69117 Heidelberg, Germany; ${ }^{5}$ Institute of Medical Informatics and Statistics (IMIS), Christian-Albrechts University, 24105 Kiel, Germany; ${ }^{6}$ Department of Human Genetics, Donders Institute for Brain, Cognition and Behavior, Radboud University Medical Center, Nijmegen 6525, The Netherlands; ${ }^{7}$ Institute of Genetic Medicine, Newcastle University, Newcastle upon Tyne NE1 3BZ, United Kingdom; ${ }^{8}$ Murray Edwards College, University of Cambridge, Cambridge CB3 ODF, United Kingdom
\end{abstract}

Abstract Whole-genome and whole-exome sequencing of individual patients allow the study of rare and potentially causative genetic variation. In this study, we sequenced DNA of a trio comprising a boy with very-early-onset inflammatory bowel disease (veolBD) and his unaffected parents. We identified a rare, $X$-linked missense variant in the NAPDH oxidase NOX1 gene (c.C721T, p.R241C) in heterozygous state in the mother and in hemizygous state in the patient. We discovered that, in addition, the patient was homozygous for a common missense variant in the CYBA gene (c.T214C, p.Y72H). CYBA encodes the p22phox protein, a cofactor for NOX1. Functional assays revealed reduced cellular ROS generation and antibacterial capacity of NOX1 and p22phox variants in intestinal epithelial cells. Moreover, the identified NADPH oxidase complex variants affected NOD2-mediated immune responses, and p22phox was identified as a novel NOD2 interactor. In conclusion, we detected missense variants in a veolBD patient that disrupt the host response to bacterial challenges and reduce protective innate immune signaling via NOD2. We assume that the patient's individual genetic makeup favored disturbed intestinal mucosal barrier function.

[Supplemental material is available for this article.]

\footnotetext{
${ }^{9}$ Present address: Department of Evolutionary Ecology, Max Planck Institute for Evolutionary Biology, 24306 Plön, Germany ${ }^{10}$ Present address: Cologne Center for Genomics, University of Cologne, 50931 Cologne, Germany

${ }^{11}$ These authors contributed equally to the work.

${ }^{12}$ The work is dedicated to the memory of Hans-Dietrich Bruhn (1937-2011).
} 


\section{INTRODUCTION}

The unraveling of the genetic etiology of Crohn's disease (CD; OMIM\#266600) provides a paradigmatic example of the successful establishment of a genetic risk map (Schreiber et al. 2005) for a polygenic human trait. More than 70 disease loci were identified and validated so far, mostly by genome-wide association studies (GWASs) or meta-analyses (Franke et al. 2010; Jostins et al. 2012) and some by exome sequencing (Mao et al. 2012; Dinwiddie et al. 2013; Ellinghaus et al. 2013).

It has been increasingly recognized that very-early-onset inflammatory bowel disease (veolBD) (Kelsen et al. 2015) is a phenocopy of adult sporadic IBD in most aspects but represents a unique disease entity. It is defined by an onset of the disease at $<6$ yr of age (Muise et al. 2012a) and is frequently caused by rare genetic variants with high penetrance. Mutations predisposing to veolBD have been identified in component genes of the reactive oxygen species (ROS)-producing nicotinamide-adenine dinucleotide phosphate (NADPH) oxidase complex-namely, NCF4 (Matute et al. 2009), NCF2/RAC2 (Muise et al. 2012b), NOX2 (Dhillon et al. 2014), and Duox2 and NOX1 (Hayes et al. 2015; Parlato et al. 2017; Schwerd et al. 2018). Impaired NADPH oxidase-mediated ROS generation is associated with higher bacterial load and a defective host immune response (Bedard and Krause 2007). Other veolBD variants were identified in IL10R (Glocker et al. 2009), IL10 (Glocker et al. 2010; Kotlarz et al. 2012), ADAM17 (Blaydon et al. 2011), XIAP (Worthey et al. 2011; Zeissig et al. 2015), TTC7A (Avitzur et al. 2014), and TRIM22 (Li et al. 2016).

In our study, a trio comprising a boy with severe, veolBD with a CD-like phenotype and his unaffected parents were subjected to whole-exome sequencing and whole-genomebased analysis. Based on previous findings in veolBD (Uhlig et al. 2014), we hypothesized that an oligogenic rather than polygenic background would underlie the etiology in this extreme case. Here, we report the identification of a rare, X-linked missense mutation in NOX1 and of a common missense variant in CYBA/p22phox. Using a combination of functional assays, we show that the variants may jointly affect innate immune function in epithelial cells, which may in turn lead to disturbed mucosal barrier function.

\section{RESULTS}

\section{Clinical Presentation and Family History}

The patient was a firstborn male delivered by lower segment cesarean because of cephalopelvic disproportion (birth weight: $8 \mathrm{lb}, 2 \mathrm{oz}$ ). No gastrointestinal diseases or other chronic inflammatory disorders had been reported in the family for the past two generations. At 2 wk, the child had a first episode of diarrhea. Because of blood in the stool at the age of $6 \mathrm{mo}$, a pediatric gastroenterologist suggested exclusion of cow milk, wheat, and soy from the diet. Bleeding continued but the child developed well and gained weight normally. At the age of $2 \mathrm{yr}$, his symptoms worsened and colonoscopy revealed unspecific colitis (indeterminate colitis). Immunosuppressive therapy with varying doses of glucocorticoid and/or azathioprine was given for $9 \mathrm{mo}$, with a markedly refractory course of the disease. At $4 \frac{1}{2} \mathrm{yr}$ of age, he developed septicemia, severe anemia (hemoglobin: $4 \mathrm{mg} / \mathrm{dL}$ ), and persistent diarrhea. Colonoscopy revealed acute ileocolitis with clear macroscopic hallmarks of CD. He was then treated with prednisolone, subcutaneous methotrexate, and infliximab but despite maximum therapy continued to have active disease at a second colonoscopy several months later. A change from infliximab to adalimumab improved the patient's condition and when combined with methotrexate and intermittent prednisolone stabilized the disease. Following genetic counseling, the family 
consented to whole-genome sequencing (WGS). Except the patient, no other relatives were genetically examined.

\section{Genomic Analyses}

WGS resulted in $>170 \mathrm{~Gb}$ of raw genomic data and an average coverage of $34 \times-40 \times$ of the reference sequence was achieved, comparable to previously published genomes (Fujimoto et al. 2010; Pelak et al. 2010; Furukawa et al. 2012). With a mapped total of 105-113 Gb per individual, $>99.5 \%$ of the respective genomes was covered by at least one read, and $>83 \%$ was covered by at least 20 reads (Supplemental Table S1).

Principal component analysis (PCA) based upon whole-genome data placed the trio closest to the European population (Supplemental Fig. S1). An average of 3.34 million SNVs per individual were called using the BioScope Software (Life Technologies, Applied Biosystems). Applying strict filtering for variants only present in the patient, 23 potential de novo coding variants were identified in the patient. However, none of these could be confirmed by Sanger sequencing, underscoring the necessity of Sanger confirmation of next-generation sequencing (NGS) variants as stated by Mu et al. (2016).

In total, 15,545 exonic SNVs were detected in the patient. Several rounds of filtering were applied to his SNVs to identify potentially causative variants. This included filtering for novel or rare potentially functional variants occurring either de novo in the patient, homozygous in the patient and heterozygous in the parents, or compound-heterozygous in the patient. We also focused on genes of interest including those related to immunodeficiencies, IBD and known disease genes for Wiskott-Aldrich syndrome (WAS), immune dysregulation, polyendocrinopathy, enteropathy, X-linked syndrome (IPEX), hyper-lgM syndrome, C1 esterase inhibitor deficiency, and X-linked agammaglobulinemia and numerous CD-like monogenic syndromes. However, despite pursuing various different approaches, no plausible candidates could be identified.

\section{Whole-Exome Sequencing}

Some 59 to 78 million reads were generated for each sample, resulting in an average on-target coverage between $46 \times$ and $62 \times$. More than $92 \%$ of the target was covered by at least 10 reads in all samples (Supplemental Table S2).

Multisample variant calling of the trio yielded a total of 81,177 on-target variants, of which 61,654 were present in the patient. We first filtered for nonsynonymous variants (i.e., missense, nonsense, start-loss, stop-loss, and splice-site variants as well as frameshift insertions and deletions [indels]), retaining 12,065 variants. Further filtering was conducted according to the variant frequencies provided by the Haplotype Reference Consortium (HRC) (Eberle et al. 2016), the Exome Aggregation Consortium (ExAC) (Lek et al. 2016), KAVIAR (Glusman et al. 2011), and the 1000 Genomes Project (Abecasis et al. 2012), allowing a maximum minor allele frequency of $1 \%$. This filtering step reduced the number further to 1821 variants. To identify candidate variants among these, we used several gene lists based upon selected publications, focusing on monogenic IBD (Uhlig 2013; Uhlig et al. 2014; Bianco et al. 2015; Uhlig and Schwerd 2016) and primary immunodeficiency genes (Al-Herz et al. 2014; Bousfiha et al. 2015; Kelsen et al. 2015; Picard et al. 2015). The remaining 21 variants (Supplemental Table S3) were examined regarding their presence in the sequenced trio and likely mode of inheritance of any associated phenotype. A rare missense variant (p.R241C) in the NOX1 (NADPH Oxidase 1) gene was present in heterozygous state in the mother and in hemizygous state in the patient. This variant had not been detected in WGS and visual inspection of the alignment revealed low coverage of this position as the probable cause, although both alleles were actually present in a small number of reads. The NOX1 variant was predicted to be damaging by FATHMM (Shihab et al. 2012) and 
Table 1. Variants detected in the exomes of a veolBD trio (after filtering)

\begin{tabular}{ccccccccc}
\hline Gene & Chromosome & $\begin{array}{c}\text { HGVS DNA } \\
\text { reference }\end{array}$ & $\begin{array}{c}\text { HGVS protein } \\
\text { reference }\end{array}$ & $\begin{array}{c}\text { Variant } \\
\text { type }\end{array}$ & $\begin{array}{c}\text { Predicted effect } \\
\text { FATHMM }\end{array}$ & $\begin{array}{c}\text { dbSNP/ } \\
\text { dbVar ID }\end{array}$ & $\begin{array}{c}\text { Parent of } \\
\text { origin }\end{array}$ \\
\hline NOX1 & ChrX & $\begin{array}{c}\text { NM_007052.4: } \\
\text { c.721C>T }\end{array}$ & $\begin{array}{c}\text { NP_008983.2:p. } \\
\text { Arg241Cys }\end{array}$ & Missense & DAMAGING & rs142303829 & Hemizygous & Mother \\
CYBA & Chr 16 & $\begin{array}{c}\text { NM_000101.2: } \\
\text { c.214T>C }\end{array}$ & $\begin{array}{c}\text { NP_000092.2:p. } \\
\text { Tyr72His }\end{array}$ & Missense & DAMAGING & rs4673 & $\begin{array}{c}\text { Homozygous } \\
\text { Mother/ } \\
\text { father }\end{array}$ \\
\hline
\end{tabular}

had a minor allele frequency of 0.002 in the ExAC and KAVIAR databases and was not present in the HRC and 1000 Genomes data (Table 1).

The other 20 filtered variants were present in heterozygous state and defects in the respective genes were reported in the literature either to follow a recessive mode of inheritance or to cause dominant disease phenotypes not fitting that of the patient (Supplemental Table S2). We therefore deemed the NOX1 variant the most likely candidate for causing disease in the patient. We also filtered for variants in genes encoding the other proteins involved in the NOX1 complex (NOXA1, RAC1, NOXO1, and CYBA). We discovered a common variant ( $\mathrm{p} . \mathrm{Y} 72 \mathrm{H}$ ) with an allele frequency of 0.69 (gnomAD) in the CYBA gene encoding for p22phox, for which the parents were heterozygous and the patient was homozygous (Table 1).

In a structural model of the NOX1 NADPH oxidase, the R241C variant was found to create a loss of positive charge in the extracellular loop between the fifth and sixth transmembrane helix (Fig. 1). The variant may interfere with an adjacent N-glycosylation site (236-239) or have a structural effect upon a potential disulfide bond (C243-C257). The $\mathrm{Y} 72 \mathrm{H}$ variant detected in p22phox likely locates in the cytosolic amino-terminal tail of the protein, although the number of transmembrane helices is still unclear (Stasia 2016). The variant is located close to a predicted protein-protein binding site (K58-K71; Ofran and Rost 2007) and

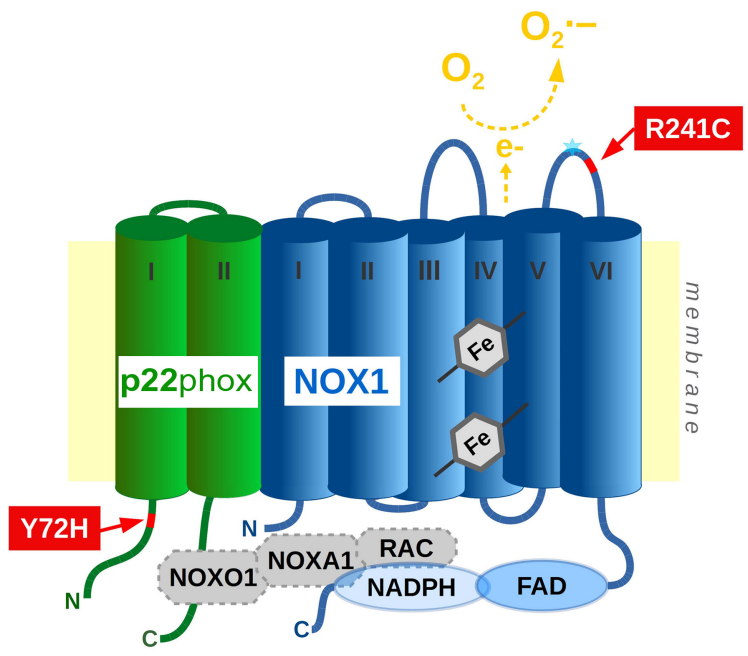

Figure 1. Schematic illustration of NOX1 R241C and p22phox Y72H localization. Predicted topology of the NADPH oxidase complex and position of the patients' variants: NOX1 is stabilized in the membrane by p22phox. Upon stimulation, recruitment of regulatory subunits NOXO1, NOXA1, and RAC proteins triggers catalysis. NOX1 variant R241C locates on the extracellular loop between transmembrane helix V and VI, adjacent to an N-glycosylation site (cyan star, pos. 236-239). In the structural model of p22phox, the $\mathrm{Y} 72 \mathrm{H}$ variant is predicted to locate on the cytosolic side. 
Table 2. Variants detected in the exomes of a veoIBD trio specifically filtered for their occurrence in the two established IBD genes, NOD2 and ATG16L1

\begin{tabular}{|c|c|c|c|c|c|c|c|c|c|c|c|c|}
\hline Father & Mother & Patient & Position & Gene & Function & Consequence & HRC & ExAC & KAVIAR & $1000 \mathrm{G}$ & DANN & FATHMM \\
\hline$w t / Y$ & mut/wt & $\mathrm{mut} / \mathrm{Y}$ & Chr X:100117243 & NOX1 & Missense & c.C721T; p.R241C & - & 0.0024 & 0.0021 & - & 0.92 & D \\
\hline mut/wt & mut/wt & mut/mut & Chr 16:88713236 & CYBA & Missense & c.T214C; p.Y72H & 0.6602 & 0.6952 & 0.6726 & 0.6643 & 0.99 & D \\
\hline $\mathrm{mut} / \mathrm{wt}$ & $\mathrm{mut} / \mathrm{mut}$ & $\mathrm{mut} / \mathrm{wt}$ & Chr 2:234183368 & ATG16L1 & Missense & c.A550G; p.T184A & 0.5253 & 0.4527 & 0.4572 & 0.3960 & 0.71 & $\mathrm{~T}$ \\
\hline mut/wt & mut/wt & $\mathrm{mut} / \mathrm{wt}$ & Chr 16:50744624 & NOD2 & Missense & c.C802T; p.P268S & 0.2593 & 0.1775 & 0.1819 & 0.1020 & 0.32 & $\mathrm{~T}$ \\
\hline mut/wt & $\mathrm{mut} / \mathrm{wt}$ & $\mathrm{mut} / \mathrm{wt}$ & Chr 16:50745199 & NOD2 & Synonymous & c.C1377T; p.R459R & 0.2609 & 0.1793 & 0.1867 & 0.1076 & 0.37 & - \\
\hline mut/wt & $w t / w t$ & mut/wt & Chr 16:50756540 & NOD2 & Missense & c.G2722C; p.G908R & 0.0116 & 0.0092 & 0.0097 & 0.0046 & 1.00 & $\mathrm{~T}$ \\
\hline
\end{tabular}

within an invariant structural motif (Taylor et al. 2011). It was previously detected in a haplotype shown to decrease ROS generation (Bedard and Krause 2007).

We also filtered variants specifically for their occurrence in the two established IBD genes, NOD2 and ATG16L1, and detected three heterozygous NOD2 variants and one heterozygous ATG16L1 variant in the patient, all of which he had inherited from one of his parents (Table 2).

The search for potential de novo mutations in the patient yielded 298 candidates. However, after visual inspection of the alignment at these positions, none of the variants could be confirmed.

\section{Functional Analysis of NADPH Oxidase Complex Variants}

Using the strategy outlined above, we identified a potentially damaging variant in NOX1 and a common variant in CYBA (p22phox) in the veolBD patient. Other rare variants in NOX1 had been previously associated with veoIBD (Hayes et al. 2015); however, the functional significance of the R241C NOX1 variant identified in the present study was unclear. Moreover, it was found to be of only very low frequency in public databases. The recurrence of the mutation in a second veolBD case would be a strong argument for its role in disease. However, because no other cases of veoIBD carrying this variant were found, we decided to study the functional consequences of the R241C variant in NOX1 and the $\mathrm{Y} 72 \mathrm{H}$ variant in p22phox in the present patient in more detail. We established plasmids encoding either NOX1 or p22phox wild-type (wt) or the R241C and Y72H variant, respectively. As expected, overexpressed wt forms of NOX1 and p22phox predominantly localized to the plasma membrane in Caco-2 cells and no alterations in their subcellular localization were observed when either $\mathrm{R} 241 \mathrm{C}$ or $\mathrm{Y} 72 \mathrm{H}$ variants were overexpressed (Fig. 2A). In view of the superoxide-generating function of the NOX1 NADPH oxidase complex, we first analyzed ROS production by wt and mutant forms of NOX1 and p22phox using a chemiluminescent assay. Caco-2 cells were transfected with either wt or mutant forms of NOX1 and p22phox and treated with the luminol derivative L-012 to detect ROS generation. Both NOX1 and p22phox are activated in response to TNF- $\alpha$ (Kim et al. 2007; Yazdanpanah et al. 2009). Thus, we used TNF- $\alpha$ in order to induce ROS production of cells. As expected, we found that overexpression of either NOX1 or p22phox wt resulted in increased superoxide levels (Fig. 2B). ROS levels were even higher when NOX1 and p22phox wt were simultaneously overexpressed. Cells that were transfected with either single $\mathrm{R} 241 \mathrm{C}$ or $\mathrm{Y} 72 \mathrm{H}$ or both variants failed to induce ROS. Next, we determined if NADPH oxidase-mediated antibacterial effects were compromised by the alleles present in the patient. In line with our expectations, compared to control, overexpression of NOX1 and p22phox wt led to strongly reduced number of cytoinvasive bacteria in a gentamycin protection assay after Listeria monocytogenes infection. Of note, the combination of wt NOX1/Y72H p22phox or R241C NOX1/wt p22phox still significantly 
A


Figure 2. Functional characterization of NOX1 and p22phox variants. (A) Immunofluorescence staining of Caco-2 cells expressing either NOX1 wt (red, upper panel, left part) or NOX1 R241C (red, upper panel, right part) and either p22phox wt (red, lower panel, left part) or p22phox Y72H (red, lower panel, right part). DAPI was used for nuclear counterstaining. Scale bar, $50 \mu \mathrm{M}$. (B) Genotype-dependent TNF- $\alpha$-induced superoxide production by NOX1 wt/R241C, p22phox wt/Y72H, and combined NOX1 + p22phox wt/wt or /R241C + Y72H in Caco-2 cells normalized to cellular protein levels. NADPH oxidase inhibitor DPI served as control. Data are representative of three independent experiments (mean of at least six in-plate replicates): $\left({ }^{*}\right) P<0.05,\left({ }^{* *}\right) P<$ 0.01 , and $\left({ }^{* * *}\right) P<0.001$. (C) Bacterial invasion in Caco-2 cells expressing NOX1 + p22phox wt, NOX1 + Y72H p22phox, R241C NOX1 + wt p22phox, or NOX1 + p22phox variants, normalized to cellular protein levels. Data are representative of three independent experiments (mean and SD of at least three in-plate replicates): (*) $P<0.05,(* *) P<0.01$ 
reduced the number of cytoinvasive bacteria, whereas the combination of R241C NOX1/ $\mathrm{Y} 72 \mathrm{H}$ p22phox failed to do so (Fig. 2C). This indicates that the combination of the two variants abrogates NADPH oxidase-mediated antibacterial activity and that their synergistic interaction may contribute to the patient's phenotype. In addition, this finding suggests that reduced antibacterial activity may predispose to an increased intracellular bacterial load. Higher bacterial burden of the intestinal epithelium leads to excess of bacterial breakdown products such as muramyl dipeptide (MDP), the elicitor of the pattern-recognition receptor NOD2.

\section{Identification of p22phox as a Novel NOD2 Interactor}

We have previously reported that NOD2 is involved in ROS generation via the NADPH oxidase DUOX2 (Lipinski et al. 2009). In addition to DUOX2, several components of the NADPH oxidase complex, including neutrophil cytosolic factor (NCF1), cytochrome b-245 $\beta$ (CYBB), and NADPH oxidase activator 1 (NOXA1), have been identified as positive regulators of the NOD2 signaling pathway in a genome-wide siRNA screen (Warner et al. 2013). Therefore, we investigated the possible link between NOD2 and NOX1/p22phox in more detail. We monitored expression levels of NOX1 and CYBA (p22phox) in response to MDP and found that stimulation with MDP led to a slight, but statistically significant upregulation of both transcripts (Fig. 3A). At the protein level, p22phox markedly increased after MDP stimulation (Fig. 3B). Next, we determined whether NOX1/p22phox and NOD2 colocalize and physically interact. Immunofluorescence showed that NOD2 and p22phox as well as NOD2 and NOX1 colocalize in transfected cell lines (Supplemental Fig. S2). Because the patient could not be recalled, we used inflamed and noninflamed intestinal biopsies from patients with $C D$ for our immunohistological analyses. In the inflamed tissue, we observed colocalization of NOD2, NOX1, and p22phox in epithelial cells (Fig. 3C), whereas the proteins did not colocalize under noninflamed conditions. We then performed coimmunoprecipitation studies and confirmed an interaction between NOD2 and p22phox proteins at the semiendogenous level (Fig. 4A), even though we were unable to detect NOX1 (data not shown). When we mapped NOD2 for domains interacting with p22phox using coimmunoprecipitation, we found that the carboxy-terminal LRR and central NBD domains are indeed required for the interaction (Supplemental Fig. S3).

\section{NADPH Oxidase Complex Variants Influence NOD2-Mediated Immune Response}

To study the impact of the allelic variants on the MDP-induced proinflammatory response via NF-kB activation, we first determined genotype-dependent effects on I $\mathrm{kB} a$ degradation, following MDP stimulation (Fig. 4B). Cells that solely expressed NOD2 showed an MDPinduced time-dependent decrease of $I_{\kappa} B a$ levels, as expected. Additional expression of NOX1 and p22phox wt induced a constant reduction of $I_{\kappa} B a$ levels, indicating elevated NF-kB activation. In contrast, mutant forms failed to induce NF-kB activation. In a second step, we used luciferase reporter assays to measure NF-kB activation (Fig. 4C). NOX1 and p22phox wt significantly increased NF-kB levels, compared to control, whereas the mutant forms failed to enhance MDP-induced NF-kB activation. Finally, we examined MDP-induced IL-8 secretion (Fig. 4D). NOX1 and p22phox wt further increased MDP-mediated IL-8 secretion, which was abrogated when the mutant forms were coexpressed with NOD2. Thus, we could confirm a genotype-dependent differential modulation of NF-kB activation in which NOX1 and p22phox act as positive regulators.

In summary, we identified a rare and a common missense variant in the NADPH oxidase complex components NOX1 and p22phox, respectively, in a male veolBD patient. We provided evidence that the allelic NOX1 variant R241C alone and in conjunction with the common p22phox variant $\mathrm{Y} 72 \mathrm{H}$ affects the enzymatic function of the NADPH oxidase 
C OLD SPRING HARBOR Molecular Case Studies
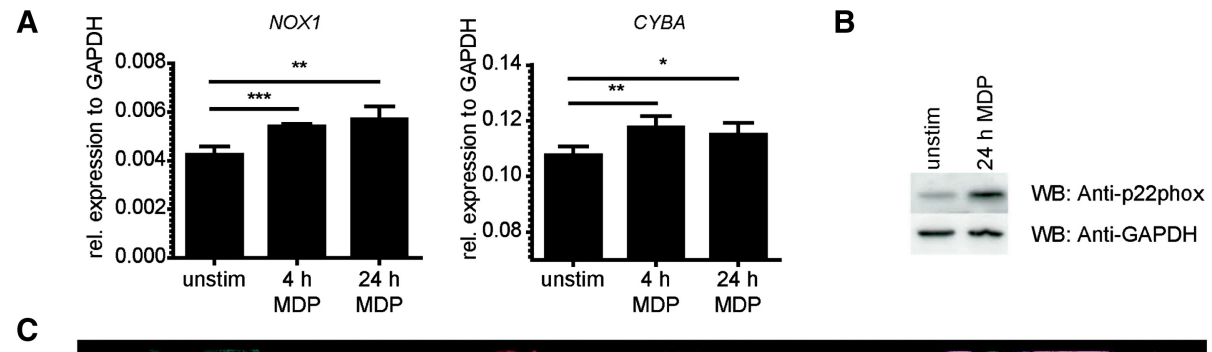

MDP MDP

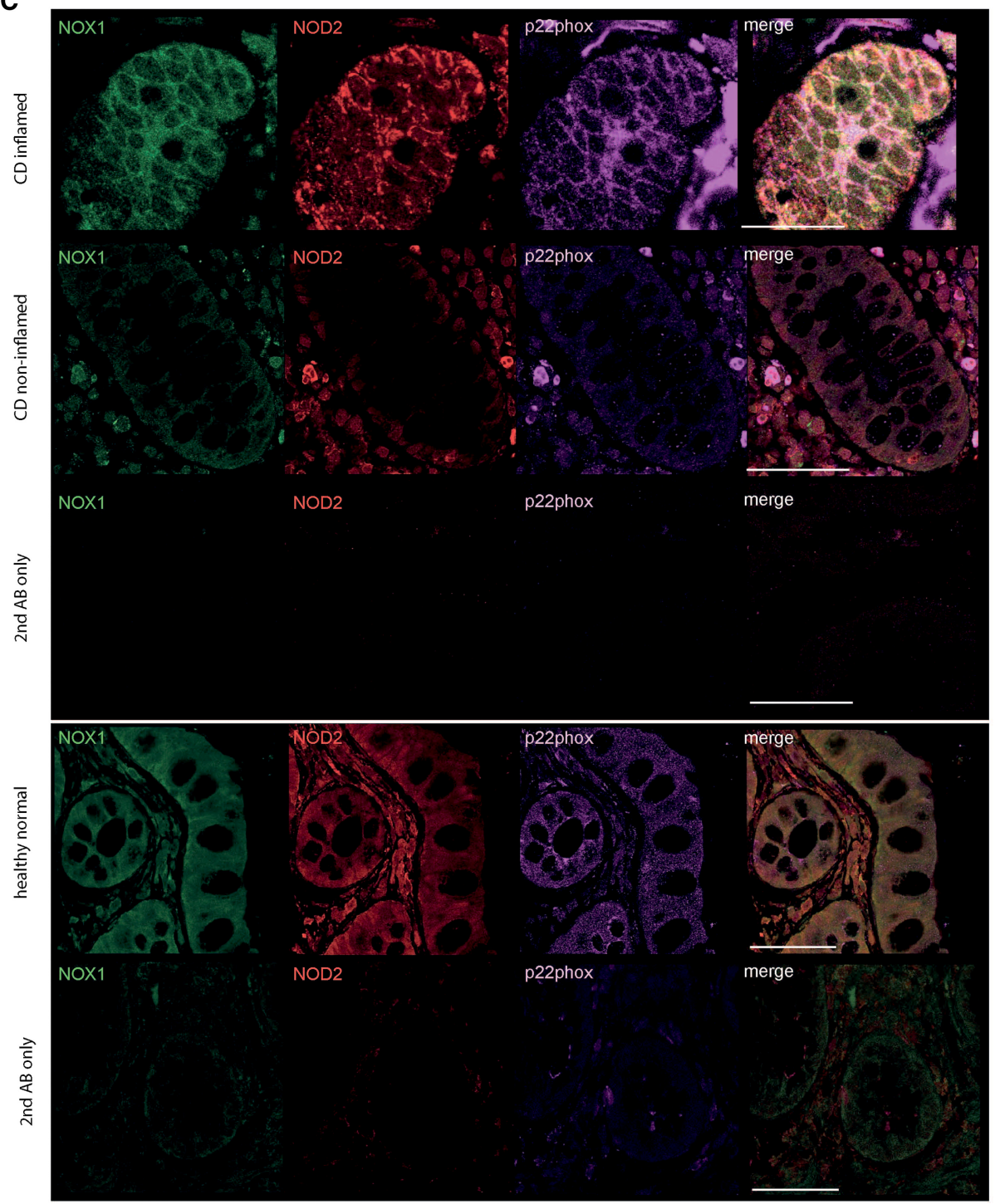

Figure 3. NOX1/p22phox induction and colocalization with NOD2. (A) MDP-induced NOX1 and CYBA expression in Caco-2 cells transfected with NOD2. Data are representative of three independent experiments (mean and SD of four in-plate replicates): $\left(^{*}\right) P<0.05,\left(^{* *}\right) P<0.01$, and $\left(^{* * *}\right) P<0.001$. (B) MDPinduced p22phox expression in Caco-2 cells transfected with NOD2. (C) Coimmunofluorescence staining of NOX1 (green), NOD2 (red), and p22phox (purple) in biopsy samples from the terminal ileum of inflamed mucosa tissue from inflamed or noninflamed Crohn's disease patients (upper panel) or healthy individuals (lower panel). For negative control, primary antibodies were omitted. Scale bar, $50 \mu \mathrm{M}$. Data are from two patient samples. 
A



B

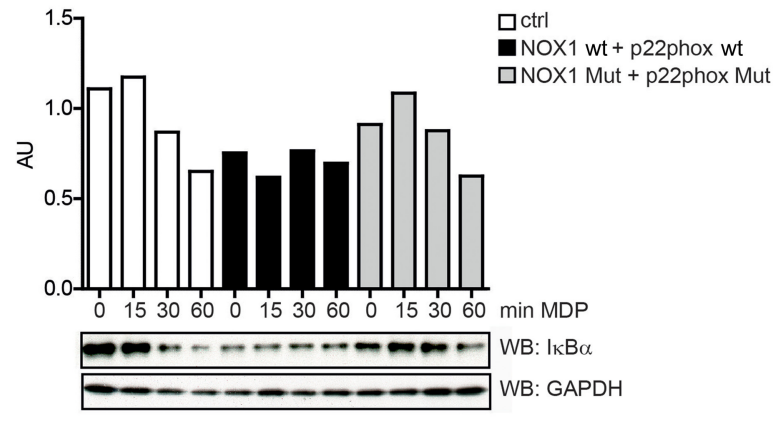

C

D


Figure 4. NOX1/p22phox interaction and functional cross talk with NOD2. (A) Semiendogenous coimmunoprecipitation of endogenous p22phox or irrelevant lgG from whole-cell lysates of NOD2-transfected HEK293 cells at $48 \mathrm{~h}$ after transfection with NOD2 and $2 \mathrm{~h}$ after stimulation with $10 \mu \mathrm{g} / \mathrm{mL}$ MDP or no treatment, followed by western blot analysis of NOD2 and p22phox. (B) Western blot and densitometric analysis of MDPmediated IкB- $\alpha$ degradation in Caco-2 cells transfected with either NOX1 and p22phox wt or mutant forms in addition to plasmids encoding NOD2. Cells were either stimulated for 15, 30, or $60 \mathrm{~min} u \operatorname{sing} 1 \mu \mathrm{g} / \mathrm{mL}$ MDP or left untreated. (C) MDP-induced NF-kB luciferase activity in Caco-2 cells transfected with either NOX1 and p22phox wt or mutant forms in addition to plasmids encoding NOD2. Stimulation was carried out for $24 \mathrm{~h}$ using $100 \mathrm{ng} / \mathrm{mL}$ or $1 \mu \mathrm{g} / \mathrm{mL}$ MDP or cells were left untreated. Luciferase activity was normalized to cellular protein levels. (D) MDP-induced IL-8 release in Caco-2 cells transfected with either NOX1 and p22phox wt or mutant forms, in addition to plasmids encoding NOD2 as assessed by ELISA. MDP stimulation was carried out for $24 \mathrm{~h}$ using $1 \mu \mathrm{g} / \mathrm{mL}$ MDP or cells were left untreated. IL-8 levels were normalized to cellular protein content. Data are representative of two $(C, E)$ or three $(D)$ independent experiments (mean and SD of six in-plate replicates): $\left(^{*}\right) P<0.05,\left(^{* *}\right) P<0.01$, and $\left(^{* * *}\right) P<0.001$.

complex. Consequent impairment of ROS levels leads to a reduced capacity of bacterial clearance. We showed a complex formation of NOD2 with NOX1/p22phox and observed a genotype-dependent dysregulation of proinflammatory signaling pathways in response to MDP. We conclude that the patient's variants in NOX1/p22phox predisposed him to disturbed intestinal epithelial barrier function. 


\section{DISCUSSION}

Whole-exome sequencing and WGS have led to the identification of rare variants in veolBD patients that accounted for their genetic disease susceptibility (Uhlig et al. 2014). Here, we described a rare missense mutation in the NAPDH oxidase NOX1 (p.R241C) in a veolBD trio comprising mother, father, and their affected son. We thereby add an additional NOX1 variant to the number of seven recently reported rare NOX1 mutations in veolBD patients (p.l67M, p.N122H, p.R287Q, p.Q293R, p.P330S, p.Y470H, and p.T497A) (Hayes et al. 2015; Schwerd et al. 2018). Although a common NOX1 variant p.D360N, with a mild lossof-function phenotype, has recently been associated with UC in Ashkenazi Jewish males, the same variant was not associated with sporadic IBD in a large Caucasian cohort (Hayes et al. 2015; Schwerd et al. 2018). Because of the presence of a relatively high load of rare variants with a strong loss-of-function effect, it is likely that even the penetrance of these variants might be incomplete (Schwerd et al. 2018). Similar to the situation in the DUOX2 gene (Pircalabioru et al. 2016), this could be because of a functional compensation or contextspecific modifiers-for example, a second variant in another IBD risk gene (second hit hypothesis) (Schwerd et al. 2018).

In addition to the NOX1 variant, our patient inherited a common variant in the CYBA gene, encoding the p.Y72H variant of p22phox, which is a component of the functional epithelial NOX1 as well as phagocytic NOX2 complexes. The $\mathrm{Y} 72 \mathrm{H}$ polymorphism of $\mathrm{p} 22 \mathrm{phox}$ was first described in chronic granulomatous disease (CGD) (Dinauer et al. 1990) and was suggested to be linked to impaired superoxide generation (Wyche et al. 2004). This is interesting in the present context, because colitis, as observed in veolBD patients, often resembles the intestinal manifestation of CGD. So far, the p22phox $Y 72 \mathrm{H}$ variant was not linked to veolBD even though a promoter SNP in CYBA, encoding p22phox, was identified by Dhillon et al. (2014) in a veolBD cohort. In our case, however, the clinical suspicion of CGD was ruled out after a normal nitroblue tetrazolium (NBT) test indicated that the p.Y72H variant did not impair ROS generation in PBMCs. Because the $\mathrm{Y} 72 \mathrm{H}$ polymorphism is a common variant, it is unlikely that it represents a bona fide veolBD risk gene. From our functional data, however, we assume that the specific genetic combination of the $\mathrm{p} 22 \mathrm{phox} Y 72 \mathrm{H}$ and the rare R241C NOX1 variant could be of importance in the patient described here. This is supported by our finding, in which combined expression of the variants exceeded the additive effect of the individual mutations on antibacterial activity, arguing for a synergistic interaction.

Furthermore, genetic variants that couple ROS deficiency to the pathogenesis of veolBD were described in several other members of the NADPH oxidase complex family (Matute et al. 2009; Muise et al. 2012a; Dhillon et al. 2014; Hayes et al. 2015; Parlato et al. 2017; for review, see O'Neill et al. 2015).

In contrast to neutrophilic NOX2, NOX1 activity is primarily found in nonphagocytic cells, especially in the intestinal epithelium (Suh et al. 1999; Bánfi et al. 2000). Intestinal epithelial ROS production exerted by NOX1 was implicated in several mechanisms contributing to the maintenance of intestinal epithelial barrier function. The suggested mechanisms include gut epithelial proliferation by symbiotic lactobacilli (Jones et al. 2013), goblet cell numbers, and postmitotic differentiation (Coant et al. 2010) as well as wound healing (Leoni et al. 2013). Although these processes clearly affect the composition of the host microbiome and cross talk between commensal bacteria and pathogens, studies on the impact of NOX1 on intestinal microbial communities are still lacking. Pircalabioru et al. (2016) used p22phox-deficient mice to demonstrate that the inactivation of epithelial NOX1 leads to an enrichment of $\mathrm{H}_{2} \mathrm{O}_{2}$-producing gut commensals. Evidence that the intestinal microbiota induces both NOX1 and p22phox expression in the small and large intestine comes from studies investigating germ-free versus conventionally raised mice (Supplemental Fig. S4; Larsson et al. 2012; Grasberger et al. 2015; Sommer et al. 2015) (data retrieved from a publicly accessible 
COLD SPRING HARBOR Molecular Case Studies
Nox1/CYBA missense variants in a veolBD patient database, http://microbiota.wall.gu.se). These findings are in line with our data showing that NOX1 and p22phox levels are up-regulated in response to stimulation with the NOD2 elicitor MDP. Notably, multiple components of the NADPH oxidase complex, including NCF1, CYBB, and NOXA1, have been identified as positive regulators of the NOD2 signaling pathway in a genome-wide siRNA screen (Warner et al. 2013). Likewise, our group previously reported that NOD2 is involved in ROS generation via the NADPH oxidase DUOX2 (Lipinski et al. 2009), thereby indicating an extensive cross talk between NOX-mediated ROS production and MDP-induced NOD2 signaling. Here, we demonstrated colocalization of NOX1, p22phox, and NOD2, a physical interaction between p22phox and NOD2, and positive regulation of NOD2-mediated NF-kB activation in the presence of NOX1 and p22phox. Thereby, we added further evidence for to the interconnection of the two innate immune mechanisms.

The effect of the genetic variants detected in our veolBD patient could be explained by a synergistic effect of the two missense variants that potentiates the failure in ROS production and antibacterial activity culminating in impaired epithelial innate defense mechanisms as suggested by Hayes et al. (2015). In addition, given the fact that mutations in NOD2 are associated with CD (for review, see Schreiber et al. 2005), and that functional NOD2 signaling is crucial for the maintenance of immune homeostasis (for review, see Philpott et al. 2014), it is likely that the loss of NOX1/p22phox-mediated positive regulation of NOD2 signaling in the patient contributed to dysbalanced mucosal homeostasis. The finding that the LRR and NBD domain of NOD2 are required to interact with the transmembrane p22phox is consistent with previous findings linking functional NOD2 signaling to the membrane (Barnich et al. 2005; Lipinski et al. 2012). Thus, in the patient, who is also heterozygous for the NOD2 loss-offunction variant G908R, protective NOD2 signaling is compromised in two ways: (i) an impairment in NOD2 function due to the G908R variant in the LRR domain and (ii) the ROS-induced NOD2 activation via the p22phox-NOD2 interaction is abrogated by loss-of-function variants in the NADPH oxidase complex. Presumably, these effects are additive, resulting in the observed phenotype. This assumption is substantiated by reports linking the veolBD risk genes TRIM22 and XIAP to altered NOD2 signaling. Variants in TRIM22 were shown to disrupt NOD2-dependent activation of interferon- $\beta$ signaling and NF- $k B$ (Li et al. 2016). Likewise, XIAP deficiency in veolBD patients is characterized by impaired NOD2 function (Worthey et al. 2011; Aguilar et al. 2014; Zeissig et al. 2015; Chirieleison et al. 2017). Furthermore, NF- $\kappa B$ activation downstream from NOD2 activation includes ubiquitination of the NF- $\mathrm{B}$ essential modulator (NEMO) (Abbott et al. 2004) and variants in NEMO are associated with monogenic form of early-onset IBD (Orange et al. 2004; Cheng et al. 2009).

Taken together, our study demonstrates that genetically attenuated ROS production by NOX1 and p22phox variants impairs innate immune defense mechanisms, including protective NOD2-dependent responses. Our case reflects a typical scenario of genetic diagnosis in rare diseases, where independent cases carrying exactly the same mutation are usually hard to find. It also demonstrates the usefulness of functional tests to demonstrate the biological impact of newly detected mutations on known disease pathways. Future efforts are required to develop and implement individualized treatment options that aim for the restoration of defective ROS production and the recovery of an effective innate host response.

\section{METHODS}

\section{Study Design \\ Whole-Genome Sequencing}

After DNA extraction, long mate-pair and paired-end libraries were generated and sequenced on the SOLiD system. Bioscope (Applied Biosystems) was used to map the raw 
COLD SPRING HARBOR Molecular Case Studies
Nox1/CYBA missense variants in a veolBD patient data against the human hg18 reference sequence and to call single nucleotide variants (SNVs) and indels (i.e., insertions and deletions). Variants were annotated using in-house scripts.

Using the WGS data, we assessed the geographic origin of all three trio members drawing upon an SNV-based PCA of 1296 individuals from 11 HapMap populations (International HapMap 3 Consortium et al. 2010), using 41,163 SNVs shared between subjects. PCA was performed using the Eigensoft (Patterson et al. 2006) with default settings and involving genotype data downloaded from the HapMap ftp site (http://hapmap.ncbi.nlm.nih.gov/ downloads/genotypes/2009-01_phaselll/plink_format/).

\section{Whole-Exome Sequencing}

The three samples were enriched using the Illumina Nextera Extended Exome Enrichment kit and DNA was sequenced in a single NextSeq run. The $2 \times 150-b p$ reads were mapped against human reference genome build hg19 using BWA (Li and Durbin 2009) v0.5.9, sorted, converted to bam format and indexed with SAMtools (Li et al. 2009) v0.1.8, followed by the removal of PCR duplicates with Picard v1.55 (http://picard.sourceforge.net). Local realignment around indels and base quality score recalibration were performed with the GATK (McKenna et al. 2010) v1.2-60 according to their best practice recommendations followed by multisample variant calling and variant quality score recalibration. ANNOVAR (Wang et al. 2010) was then used for annotation, allowing for variant filtering based upon frequency, functional consequence, location in candidate genes and the output of several prediction tools. Potential de novo mutations were identified using VarScan (Koboldt et al. 2012) trio de novo analysis with subsequent visual inspection of the alignment in the integrative genomics viewer (IGV) (Robinson et al. 2011).

\section{Cell Culture, Reagents, and Transfection}

HEK293 and Caco-2 cells were purchased from the German Collection of Microorganisms and Cell Cultures (DSMZ). HEK293 cells were maintained in DMEM containing 10\% (v/v) fetal calf serum (FCS). Caco-2 cells were maintained in MEM containing 20\% (v/v) FCS. Cells were kept at $37^{\circ} \mathrm{C}$ with $5 \% \mathrm{CO}_{2}$. Recombinant TNF-a was purchased from ImmunoTools, muramyl dipeptide (MurNAc-L-Ala-D-isoGln, MDP) from Bachem and diphenyleneiodonium chloride (DPI) from Sigma. p22phox (rb) antibody was purchased from Santa Cruz (sc-20781), NOD2 (rb, ms) antibodies from Novus Biologicals (rb: NB 500-253, ms: NB 100-524), Anti-Flag (ms) from Sigma (F1804), Anti-DDK (ms) from Origene (TA50011-100), Anti-GFP (rb) from BD (632377), Anti-IkBa (rb) from CST (2859) and Rabbit TrueBlot from Life Technologies (18-8816-33). All HRP-conjugated secondary antibodies were obtained from TH Geyer (ms: NA931V). AF-488-(A21206, A11055), AF-555-(A31570, A31572), and AF633-(A21082, A21052) conjugated secondary antibodies were purchased from Invitrogen. Transfections were performed using Fugeneb according to manufacturer's instructions (Roche).

\section{Plasmids and Mutagenesis}

Plasmids encoding the full-length wild-type coding sequences of NOX1 and p22phox were purchased from Origene (pCMV6-NOX1 [NM007052, \#RC210426] and pCMV6-CYBA [NM000101, \#RC2007069). The Q5 Site-Directed Mutagenesis Kit (NEB) was used to generate mutated NOX1 p.R241C (corresponding to rs142303829 allele C721T) and p22phox p. Y72H (corresponding to rs4673 allele T214C). The following primers were used: pNOX1_f: GAGTCATCCTtGCAAGTGTGC, pNOX1_r: TCATTCATGCTCTCCTCTG, pCYBA_f: GGG ACAGAAGcACATGACCGC, pCBYA_r: CAGCGCTCCATGGTGGAG. Mutations were verified by Sanger sequencing. NOD2 plasmid (pcDNA3-NOD2) was kindly provided by G. Nunez (Ann Arbor, MI). EGFP-NOD2 fusion protein was generated by inserting the 
COLD SPRING HARBOR Molecular Case Studies
Nox1/CYBA missense variants in a veolBD patient
NOD2 coding sequence into $\mathrm{pEGFP-C} 3$ vector using the Hindlll and BamHI restriction sites. Expression vector for NOX1-GFP was a kind gift of E. Meccia (Rome, Italy).

\section{ROS Assays}

ROS generation was measured using the luminol derivative L-012 (Wako), a highly sensitive chemiluminescence probe as described by Daiber et al. (2004). In brief, Caco-2 cells were incubated with $500 \mu \mathrm{M} \mathrm{L-012} \mathrm{for} 30 \mathrm{~min}$, washed with PBS, and stimulated with TNF-a. The NOX inhibitor DPI was used at $10 \mu \mathrm{M}$ to suppress TNF- $\alpha$-induced ROS generation and shows reliability of the assay. Chemiluminescence was determined before the addition of TNF- $\alpha$ and every $10 \mathrm{~min}$ thereafter. Superoxide generation was calculated as difference in luminescence intensity between baseline and $t=30 \mathrm{~min}$.

\section{Gentamicin Protection Assay (GPA)}

Listeria monocytogenes serotype 1/2a strain EGD was used for cytoinvasion assay. Bacteria were plated out onto $\mathrm{BHI}$ plates overnight. Listeria colonies were then transferred into $1 \mathrm{~mL}$ $\mathrm{BHI}$ medium and incubated overnight at $37^{\circ} \mathrm{C}$ for amplification of bacteria. Bacterial culture was diluted to induce a log-phase growth until $\mathrm{OD} 600=0.6$ was reached. Bacteria were washed in PBS and resuspended in cell culture media without FBS.

Caco-2 cells were incubated with $L$. monocytogenes $(\mathrm{MOI}=100)$ at $37^{\circ} \mathrm{C}$ for $1 \mathrm{~h}$. After one washing step with PBS, cells were treated with gentamicin $(50 \mu \mathrm{g} / \mathrm{mL}$ media) for $1 \mathrm{~h}$. Cells were then lysed in $50 \mu \mathrm{L} 1 \%$ Triton X-100/PBS. After dilution of 1:100 in PBS, $5 \mu \mathrm{L}$ of the lysates were plated out onto BHI plates using glass bead spread method (Rattler Plating Beads). Plates were then incubated at $37^{\circ} \mathrm{C}$ and $5 \% \mathrm{CO}_{2}$ for $24 \mathrm{~h}$. Colonies were counted to determine colony-forming units (CFU) of survived bacteria. CFU were normalized to protein content of Caco-2 cell lysates, as determined by bicinchoninic acid (BCA) assay (Pierce, USA).

\section{Coimmunoprecipitation and Western Blots}

HEK293 cells were transfected as indicated with plasmids for NOX1 (wt or R241C), p22phox (wt or Y72H), NOD2, Flag-tagged CARD-, NBD-, or LRR domains of NOD2 or vector controls. At $24 \mathrm{~h}$ after transfection, cells were lysed in RIPA buffer $(50 \mathrm{mM}$ Tris/ $\mathrm{HCl}, \mathrm{pH} 7.4,150 \mathrm{mM}$ $\mathrm{NaCl}, 0.25 \% \mathrm{Na}$-deoxycholate, $1 \% \mathrm{NP}-40,0.1 \% \mathrm{SDS}$ ) in the presence of protease inhibitors. Proteins were pulled using Dynabeads (Invitrogen) and antibodies against p22phox, IgG control, DDK-Tag, or GFP. Precipitates were washed, eluted, and separated by SDSPAGE. After transfer onto polyvinylidene difluoride membranes (Millipore), membranes were blocked with $5 \%$ nonfat-dried milk and probed with primary antibodies as indicated, washed, and incubated with peroxidase-conjugated secondary antibodies. Proteins were visualized using chemiluminescent substrates ( $E C L$, Amersham Biosciences) and exposure to X-ray films (Hyperfilm, Amersham).

\section{Transfection, NF-кB Luciferase Reporter Assay, and ELISA}

Caco-2 cells were plated in 96-well plates and transfected using Fugene 6 using $12 \mathrm{ng} /$ well of pNF-kB-Luciferase plasmid (Stratagene, USA), 2 ng/well NOD2 plasmids, $28 \mathrm{ng} /$ well NOX1 wt or Mut plasmids and $5 \mathrm{ng} /$ well p22phox wt or Mut plasmids as indicated. Cells were either stimulated for $24 \mathrm{~h}$ using $100 \mathrm{ng} / \mathrm{mL}$ or $1 \mu \mathrm{g} / \mathrm{mL}$ MDP or left untreated. NF-kB-dependent luciferase activity was determined using a luciferase reporter gene kit (Promega, USA). Supernatants were used for determination of IL-8 levels. Luciferase activity and cytokine release were normalized to protein content, as determined by BCA assay (Pierce, USA). 
COLD SPRING HARBOR Molecular Case Studies
Nox1/CYBA missense variants in a veolBD patient

\section{Microscopy}

Caco-2 cells were seeded on coverslips and transfected as indicated. The following day, cells were washed, fixed in 4\% paraformaldehyde-PBS, blocked for $1 \mathrm{~h}$ in $1 \%$ BSA-PBS and stained using antibodies as indicated. DAPI was used for DNA counterstaining. Images were acquired using a Zeiss Axiolmager.Z1 apotome fluorescence microscope and the AxioVision Imaging software (Carl Zeiss Microlmaging Inc.). Confocal microscopy was performed using the Leica TCS SP5 AOBS confocal microscopy system equipped with a HCX PL APO CS 63x/1.2 water UV objective. Images were captured with a voxel size of $75.2 \mathrm{~nm}$ in sequential scan mode to exclude cross talk between channels. Different treatments within one experiment were captured with identical instrument settings. Analysis was done using Leica Application Suite AF 2.3.6 and ImageJ 1.44 (National Institutes of Health, USA) including ImageJ Plugin LOCI Bio-Formats library as published in Linkert et al. (2010).

\section{Patient Samples}

Mucosal colonic biopsies from patients with CD were extracted as previously described (Waetzig et al. 2002). Biopsies from healthy individuals were derived from patients without pathological conditions during colonoscopy for routine clinical evaluation. For whole-exome sequencing, DNA was extracted from whole blood of the diseased child and his unaffected parents.

\section{Expression Analysis}

Taqman assays were ordered from Applied Biosystems. Total RNA (1 $\mu \mathrm{g})$ was reversetranscribed to cDNA according to the manufacturer's instructions (MultiScribe Reverse Transcriptase, Applied Biosystems). Reactions were carried out on the ABI PRISM Sequence 7700 Detection System (Applied Biosystems) and relative transcript levels were determined using GAPDH as a housekeeper marker using the standard curve method (Livak and Schmittgen 2001).

\section{Statistical Analysis}

All continuous data were presented as mean \pm SD estimated from at least three independent experiments and analyzed for significant group differences using a two-tailed unpaired Student's $t$-test. $P$ values $<0.05$ were considered statistically significant $\left(^{*}\right) P<0.05,\left(^{* *}\right) P<$ 0.01 , and $(* * *) P<0.001$. GraphPad Prism5 was used for visualization.

\section{ADDITIONAL INFORMATION}

\section{Data Deposition and Access}

The reported variants were submitted to ClinVar (https://www.ncbi.nlm.nih.gov/clinvar/) and can be found under accession numbers SCV000864163 and SCV000864164. Raw sequencing data were not deposited because of lack of patient consent.

\section{Ethics Statement}

All study-related procedures were approved by the Ethics Committee of the Medical Faculty of Kiel University (reference \#B231/98-1/13 and \#A156/03). All study participants agreed to participate by giving informed consent at least $24 \mathrm{~h}$ before the study.

\section{Acknowledgments}

The authors are greatly indebted to the patient and his family for participating in this study. We want to thank all clinicians who were involved in taking care of the patient, especially 
Competing Interest Statement

V.S. and C.C.L. are employees of Life Technologies (Thermo Fisher); all other authors have nothing to disclose in relation to this work.

Received November 8, 2017; accepted in revised form October 29, 2018.
Prof. Peter J. Milla, Gastroenterology Unit, UCL Institute of Child Health, University College London, UK and Dr. Mamoun Elawad, Department of Paediatric Gastroenterology, Great Ormond Street Hospital, London, UK. The study was supported by a nonrestricted grant from Life Technologies, which did not influence the conception of the study. We thank Lena Bossen, Melanie Schlapkohl, Melanie Vollstedt, Catharina von der Lancken, Anita Dietsch, Maren Reffelmann, Sabine Kock, Melanie Nebendahl, Dorina Ölsner, Tanja Klostermeier, Katharina Göbel, Tatjana Schmidtke, Tanja Wesse, Tanja Naujoks, Susan Ehlers, and Karina Greve for their expert technical assistance.

\section{Author Contributions}

S.L., B.-S.P., M.B., A.P., F.T., G.M., M.J., and S.T.S. performed experiments and analyzed the data. B.-S.P. and C.C.L. coordinated whole-exome and whole-genome sequencing. U.C.K. prepared DNA/RNA for sequencing. Bioinformatics analyses were performed by B.-S.P., M.B., and P.R. with contributions by V.S., D.E., T.R., J.O.K., C.G., J.A.V., M.F., and P.F. Statistical advice was given by M.N. and M.K. The manuscript was prepared by S.L., B.-S.P., M.B., and P.R., with the participation of A.F. A.F.-R., S.T.S., A.F., and P.R. conceived the study and supervised the work. All authors discussed the results and commented on the manuscript.

\section{Funding}

This work was partially supported by Deutsche Forschungsgemeinschaft (DFG), Clusters of Excellence "Inflammation at Interfaces" (EXC306) and "Future Ocean" (EXC80), DFG grant FR 2821/6-1, Bundesministerium für Bildung und Forschung (BMBF) E:med consortium Sysinflame through grant 012X1306F, SFB 877 subproject B9 (PR) and the EU FP 7 grant SysMedIBD (WP8 Genomics to P.R. and S.S.) grant 305564. M.B. received a scholarship from the Bruhn-Foundation. The work is dedicated to the memory of Hans-Dietrich Bruhn (1937-2011).

\section{REFERENCES}

Abbott DW, Wilkins A, Asara JM, Cantley LC. 2004. The Crohn's disease protein, NOD2, requires RIP2 in order to induce ubiquitinylation of a novel site on NEMO. Curr Biol 14: 2217-2227. doi:10.1016/j.cub .2004.12.032

Abecasis GR, Auton A, Brooks LD, DePristo MA, Durbin RM, Handsaker RE, Kang HM, Marth GT, McVean GA. 2012. An integrated map of genetic variation from 1,092 human genomes. Nature 491: 56-65. doi:10.1038/nature11632

Aguilar C, Lenoir C, Lambert N, Bègue B, Brousse N, Canioni D, Berrebi D, Roy M, Gérart S, Chapel H, et al. 2014. Characterization of Crohn disease in $X$-linked inhibitor of apoptosis-deficient male patients and female symptomatic carriers. J Allergy Clin Immunol 134: 1131-1141.e9. doi:10.1016/j.jaci.2014.04.031

Al-Herz W, Bousfiha A, Casanova J-L, Chatila T, Conley ME, Cunningham-Rundles C, Etzioni A, Franco JL, Gaspar HB, Holland SM, et al. 2014. Primary immunodeficiency diseases: an update on the classification from the international union of immunological societies expert committee for primary immunodeficiency. Front Immunol 5: 62. doi:10.3389/fimmu.2014.00162

Avitzur Y, Guo C, Mastropaolo LA, Bahrami E, Chen H, Zhao Z, Elkadri A, Dhillon S, Murchie R, Fattouh R, et al. 2014. Mutations in tetratricopeptide repeat domain 7A result in a severe form of very early onset inflammatory bowel disease. Gastroenterology 146: 1028-1039. doi:10.1053/j.gastro.2014.01.015

Bánfi B, Maturana A, Jaconi S, Arnaudeau S, Laforge T, Sinha B, Ligeti E, Demaurex N, Krause KH. 2000. A mammalian $\mathrm{H}^{+}$channel generated through alternative splicing of the $\mathrm{NADPH}$ oxidase homolog $\mathrm{NOH}-1$. Science 287: 138-142. doi:10.1126/science.287.5450.138

Barnich N, Aguirre JE, Reinecker HC, Xavier R, Podolsky DK. 2005. Membrane recruitment of NOD2 in intestinal epithelial cells is essential for nuclear factor- $\kappa B$ activation in muramyl dipeptide recognition. $J$ Cell Biol 170: 21-26. doi:10.1083/jcb.200502153

Bedard K, Krause KH. 2007. The NOX family of ROS-generating NADPH oxidases: physiology and pathophysiology. Physiol Rev 87: 245-313. doi:10.1152/physrev.00044.2005 
Bianco AM, Girardelli M, Tommasini A. 2015. Genetics of inflammatory bowel disease from multifactorial to monogenic forms. World J Gastroenterol 21: 12296-12310. doi:10.3748/wjg.v21.i43.12296

Blaydon DC, Biancheri P, Di WL, Plagnol V, Cabral RM, Brooke MA, van Heel DA, Ruschendorf F, Toynbee M, Walne A, et al. 2011. Inflammatory skin and bowel disease linked to ADAM17 deletion. N Engl J Med 365: 1502-1508. doi:10.1056/NEJMoa1100721

Bousfiha A, Jeddane L, Al-Herz W, Ailal F, Casanova J-L, Chatila T, Conley ME, Cunningham-Rundles C, Etzioni A, Franco JL, et al. 2015. The 2015 IUIS phenotypic classification for primary immunodeficiencies. J Clin Immunol 35: 727-738. doi:10.1007/s10875-015-0198-5

Cheng LE, Kanwar B, Tcheurekdjian H, Grenert JP, Muskat M, Heyman MB, McCune JM, Wara DW. 2009. Persistent systemic inflammation and atypical enterocolitis in patients with NEMO syndrome. Clin Immunol 132: 124-131. doi:10.1016/j.clim.2009.03.514

Chirieleison SM, Marsh RA, Kumar P, Rathkey JK, Dubyak GR, Abbott DW. 2017. Nucleotide-binding oligomerization domain (NOD) signaling defects and cell death susceptibility cannot be uncoupled in X-linked inhibitor of apoptosis (XIAP)-driven inflammatory disease. J Biol Chem 292: 9666-9679. doi:10.1074/ jbc.M117.781500

Coant N, Ben Mkaddem S, Pedruzzi E, Guichard C, Tréton X, Ducroc R, Freund JN, Cazals-Hatem D, Bouhnik Y, Woerther PL, et al. 2010. NADPH oxidase 1 modulates WNT and NOTCH1 signaling to control the fate of proliferative progenitor cells in the colon. Mol Cell Biol 30: 2636-2650. doi:10.1128/ MCB.01194-09

Daiber A, August M, Baldus S, Wendt M, Oelze M, Sydow K, Kleschyov AL, Munzel T. 2004. Measurement of $\mathrm{NAD}(\mathrm{P}) \mathrm{H}$ oxidase-derived superoxide with the luminol analogue L-012. Free Radic Biol Med 36: 101-111. doi:10.1016/j.freeradbiomed.2003.10.012

Dhillon SS, Fattouh R, Elkadri A, Xu W, Murchie R, Walters T, Guo C, Mack D, Huynh HQ, Baksh S, et al. 2014. Variants in nicotinamide adenine dinucleotide phosphate oxidase complex components determine susceptibility to very early onset inflammatory bowel disease. Gastroenterology 147: 680-689.e2. doi:10 .1053/j.gastro.2014.06.005

Dinauer MC, Pierce EA, Bruns GA, Curnutte JT, Orkin SH. 1990. Human neutrophil cytochrome b light chain (p22-phox). Gene structure, chromosomal location, and mutations in cytochrome-negative autosomal recessive chronic granulomatous disease. J Clin Invest 86: 1729-1737. doi:10.1172/JCI114898

Dinwiddie DL, Bracken JM, Bass JA, Christenson K, Soden SE, Saunders CJ, Miller NA, Singh V, Zwick DL, Roberts CC, et al. 2013. Molecular diagnosis of infantile onset inflammatory bowel disease by exome sequencing. Genomics 102: 442-447. doi:10.1016/j.ygeno.2013.08.008

Eberle MA, Fritzilas E, Krusche P, Källberg M, Moore BL, Bekritsky MA, lqbal Z, Chuang H-Y, Humphray SJ, Halpern AL, et al. 2016. A reference data set of 5.4 million phased human variants validated by genetic inheritance from sequencing a three-generation 17-member pedigree. Genome Res 27: 157-164. doi:10.1101/gr.210500.116.

Ellinghaus D, Zhang H, Zeissig S, Lipinski S, Till A, Jiang T, Stade B, Bromberg Y, Ellinghaus E, Keller A, et al. 2013. Association between variants of PRDM1 and NDP52 and Crohn's disease, based on exome sequencing and functional studies. Gastroenterology 145: 339-347. doi:10.1053/j.gastro.2013.04.040

Franke A, McGovern DP, Barrett JC, Wang K, Radford-Smith GL, Ahmad T, Lees CW, Balschun T, Lee J, Roberts R, et al. 2010. Genome-wide meta-analysis increases to 71 the number of confirmed Crohn's disease susceptibility loci. Nat Genet 42: 1118-1125. doi:10.1038/ng.717

Fujimoto A, Nakagawa H, Hosono N, Nakano K, Abe T, Ka B, Nagasaki M, Yamaguchi R, Shibuya T, Kubo M, et al. 2010. Whole-genome sequencing and comprehensive variant analysis of a Japanese individual using massively parallel sequencing. Nat Genet 42: 931-936. doi:10.1038/ng.691

Furukawa H, Oka S, Matsui T, Hashimoto A, Arinuma Y, Komiya A, Fukui N, Tsuchiya N, Tohma S. 2012. Genome, epigenome and transcriptome analyses of a pair of monozygotic twins discordant for systemic lupus erythematosus. Human Immunol 74: 170-175. doi:10.1016/j.humimm.2012.11.007.

Glocker EO, Kotlarz D, Boztug K, Gertz EM, Schäffer AA, Noyan F, Perro M, Diestelhorst J, Allroth A, Murugan $D$, et al. 2009. Inflammatory bowel disease and mutations affecting the interleukin-10 receptor. N Engl J Med 361: 2033-2045. doi:10.1056/NEJMoa0907206

Glocker EO, Frede N, Perro M, Sebire N, Elawad M, Shah N, Grimbacher B. 2010. Infant colitis-it's in the genes. Lancet 376: 1272. doi:10.1016/S0140-6736(10)61008-2

Glusman G, Caballero J, Mauldin DE, Hood L, Roach JC. 2011. Kaviar: an accessible system for testing SNV novelty. Bioinformatics 27: 3216-3217. doi:10.1093/bioinformatics/btr540

Grasberger H, Gao J, Nagao-Kitamoto H, Kitamoto S, Zhang M, Kamada N, Eaton KA, El-Zaatari M, Shreiner AB, Merchant JL, et al. 2015. Increased expression of DUOX2 is an epithelial response to mucosal dysbiosis required for immune homeostasis in mouse intestine. Gastroenterology 149: 1849-1859. doi:10.1053/ j.gastro.2015.07.062 
Hayes P, Dhillon S, O’Neill K, Thoeni C, Hui KY, Elkadri A, Guo CH, Kovacic L, Aviello G, Alvarez LA, et al. 2015. Defects in NADPH oxidase genes NOX1 and DUOX2 in very early onset inflammatory bowel disease. Cell Mol Gastroenterol Hepatol 1: 489-502. doi:10.1016/j.jcmgh.2015.06.005

International HapMap 3 Consortium, Altshuler DM, Gibbs RA, Peltonen L, Altshuler DM, Gibbs RA, Peltonen L, Dermitzakis E, Schaffner SF, Yu F, et al. 2010. Integrating common and rare genetic variation in diverse human populations. Nature 467: 52-58. doi:10.1038/nature09298

Jones RM, Luo L, Ardita CS, Richardson AN, Kwon YM, Mercante JW, Alam A, Gates CL, Wu H, Swanson PA, et al. 2013. Symbiotic lactobacilli stimulate gut epithelial proliferation via Nox-mediated generation of reactive oxygen species. EMBO J 32: 3017-3028. doi:10.1038/emboj.2013.224

Jostins L, Ripke S, Weersma RK, Duerr RH, McGovern DP, Hui KY, Lee JC, Schumm LP, Sharma Y, Anderson CA, et al. 2012. Host-microbe interactions have shaped the genetic architecture of inflammatory bowel disease. Nature 491: 119-124. doi:10.1038/nature11582

Kelsen JR, Dawany N, Moran CJ, Petersen B-S, Sarmady M, Sasson A, Pauly-Hubbard H, Martinez A, Maurer K, Soong J, et al. 2015. Exome sequencing analysis reveals variants in primary immunodeficiency genes in patients with very early onset inflammatory bowel disease. Gastroenterology 149: 1415-1424. doi:10.1053/j.gastro.2015.07.006

Kim YS, Morgan MJ, Choksi S, Liu ZG. 2007. TNF-induced activation of the Nox1 NADPH oxidase and its role in the induction of necrotic cell death. Mol Cell 26: 675-687. doi:10.1016/j.molcel.2007.04.021

Koboldt DC, Zhang Q, Larson DE, Shen D, McLellan MD, Lin L, Miller CA, Mardis ER, Ding L, Wilson RK. 2012. VarScan 2: somatic mutation and copy number alteration discovery in cancer by exome sequencing. Genome Res 22: 568-576. doi:10.1101/gr.129684.111

Kotlarz D, Beier R, Murugan D, Diestelhorst J, Jensen O, Boztug K, Pfeifer D, Kreipe H, Pfister ED, Baumann U, et al. 2012. Loss of interleukin-10 signaling and infantile inflammatory bowel disease: implications for diagnosis and therapy. Gastroenterology 143: 347-355. doi:10.1053/j.gastro.2012.04.045

Larsson E, Tremaroli V, Lee YS, Koren O, Nookaew I, Fricker A, Nielsen J, Ley RE, Bäckhed F. 2012. Analysis of gut microbial regulation of host gene expression along the length of the gut and regulation of gut microbial ecology through MyD88. Gut 61: 1124-1131. doi:10.1136/gutjnl-2011-301104

Lek M, Karczewski KJ, Minikel EV, Samocha KE, Banks E, Fennell T, O’Donnell-Luria AH, Ware JS, Hill AJ, Cummings BB, et al. 2016. Analysis of protein-coding genetic variation in 60,706 humans. Nature 536: 285-291. doi:10.1038/nature19057

Leoni G, Alam A, Neumann PA, Lambeth JD, Cheng G, McCoy J, Hilgarth RS, Kundu K, Murthy N, Kusters D, et al. 2013. Annexin A1, formyl peptide receptor, and NOX1 orchestrate epithelial repair. J Clin Invest 123: 443-454. doi:10.1172/JCl65831

Li H, Durbin R. 2009. Fast and accurate short read alignment with Burrows-Wheeler transform. Bioinformatics 25: 1754-1760. doi:10.1093/bioinformatics/btp324

Li H, Handsaker B, Wysoker A, Fennell T, Ruan J, Homer N, Marth G, Abecasis G, Durbin R, 1000 Genome Project Data Processing Subgroup. 2009. The sequence alignment/map format and SAMtools. Bioinformatics 25: 2078-2079. doi:10.1093/bioinformatics/btp352

Li Q, Lee CH, Peters LA, Mastropaolo LA, Thoeni C, Elkadri A, Schwerd T, Zhu J, Zhang B, Zhao Y, et al. 2016. Variants in TRIM22 that affect NOD2 signaling are associated with very-early-onset inflammatory bowel disease. Gastroenterology 150: 1196-1207. doi:10.1053/j.gastro.2016.01.031

Linkert M, Rueden CT, Allan C, Burel JM, Moore W, Patterson A, Loranger B, Moore J, Neves C, MacDonald D, et al. 2010. Metadata matters: access to image data in the real world. J Cell Biol 189: 777-782. doi: 10.1083/jcb.201004104

Lipinski S, Till A, Sina C, Arlt A, Grasberger H, Schreiber S, Rosenstiel P. 2009. DUOX2-derived reactive oxygen species are effectors of NOD2-mediated antibacterial responses. J Cell Sci 122: 3522-3530. doi:10.1242/ jcs.050690

Lipinski S, Grabe N, Jacobs G, Billmann-Born S, Till A, Häsler R, Aden K, Paulsen M, Arlt A, Kraemer L, et al. 2012. RNAi screening identifies mediators of NOD2 signaling: implications for spatial specificity of MDP recognition. Proc Natl Acad Sci 109: 21426-21431. doi:10.1073/pnas.1209673109

Livak KJ, Schmittgen TD. 2001. Analysis of relative gene expression data using real-time quantitative PCR and the $2^{-\Delta \Delta C_{T}}$ method. Methods 25: 402-408. doi:10.1006/meth.2001.1262

Mao H, Yang W, Lee PP, Ho MH, Yang J, Zeng S, Chong CY, Lee TL, Tu W, Lau YL. 2012. Exome sequencing identifies novel compound heterozygous mutations of IL-10 receptor 1 in neonatal-onset Crohn's disease. Genes Immun 13: 437-442. doi:10.1038/gene.2012.8

Matute JD, Arias AA, Wright NA, Wrobel I, Waterhouse CC, Li XJ, Marchal CC, Stull ND, Lewis DB, Steele M, et al. 2009. A new genetic subgroup of chronic granulomatous disease with autosomal recessive mutations in p40 $^{\text {phox }}$ and selective defects in neutrophil NADPH oxidase activity. Blood 114: 3309-3315. doi: 10.1182/blood-2009-07-231498 
McKenna A, Hanna M, Banks E, Sivachenko A, Cibulskis K, Kernytsky A, Garimella K, Altshuler D, Gabriel S, Daly M, et al. 2010. The Genome Analysis Toolkit: a MapReduce framework for analyzing next-generation DNA sequencing data. Genome Res 20: 1297-1303. doi:10.1101/gr.107524.110

Mu W, Lu HM, Chen J, Li S, Elliott AM. 2016. Sanger confirmation is required to achieve optimal sensitivity and specificity in next-generation sequencing panel testing. J Mol Diagn 18: 923-932. doi:10.1016/ j.jmoldx.2016.07.006

Muise AM, Snapper SB, Kugathasan S. 2012a. The age of gene discovery in very early onset inflammatory bowel disease. Gastroenterology 143: 285-288. doi:10.1053/j.gastro.2012.06.025

Muise AM, Xu W, Guo CH, Walters TD, Wolters VM, Fattouh R, Lam GY, Hu P, Murchie R, Sherlock M, et al. 2012b. NADPH oxidase complex and IBD candidate gene studies: identification of a rare variant in NCF2 that results in reduced binding to RAC2. Gut 61: 1028-1035. doi:10.1136/gutjnl-2011300078

Ofran Y, Rost B. 2007. ISIS: interaction sites identified from sequence. Bioinformatics 23: e13-e16. doi: 10.1093/bioinformatics/btl303

O'Neill S, Brault J, Stasia MJ, Knaus UG. 2015. Genetic disorders coupled to ROS deficiency. Redox Biol 6: 135-156. doi:10.1016/j.redox.2015.07.009

Orange JS, Jain A, Ballas ZK, Schneider LC, Geha RS, Bonilla FA. 2004. The presentation and natural history of immunodeficiency caused by nuclear factor $\mathrm{kB}$ essential modulator mutation. J Allergy Clin Immunol 113: 725-733. doi:10.1016/j.jaci.2004.01.762

Parlato M, Charbit-Henrion F, Hayes P, Tiberti A, Aloi M, Cucchiara S, Bègue B, Bras M, Pouliet A, Rakotobe S, et al. 2017. First identification of biallelic inherited DUOX2 inactivating mutations as a cause of very early onset inflammatory bowel disease. Gastroenterology 3: 35484-35487.

Patterson N, Price AL, Reich D. 2006. Population structure and eigenanalysis. PLoS Genet 2: 2074-2093. doi:10.1371/journal.pgen.0020190

Pelak K, Shianna KV, Ge D, Maia JM, Zhu M, Smith JP, Cirulli ET, Fellay J, Dickson SP, Gumbs CE, et al. 2010. The characterization of twenty sequenced human genomes. PLoS Genet 6. doi:10.1371/journal.pgen .1001111

Philpott DJ, Sorbara MT, Robertson SJ, Croitoru K, Girardin SE. 2014. NOD proteins: regulators of inflammation in health and disease. Nat Rev Immunol 14: 9-23. doi:10.1038/nri3565

Picard C, Al-Herz W, Bousfiha A, Casanova J-L, Chatila T, Conley ME, Cunningham-Rundles C, Etzioni A, Holland SM, Klein C, et al. 2015. Primary immunodeficiency diseases: an update on the classification from the International Union of Immunological Societies Expert Committee for Primary Immunodeficiency 2015 J Clin Immunol 35: 696-726. doi:10.1007/s10875-015-0201-1.

Pircalabioru G, Aviello G, Kubica M, Zhdanov A, Paclet MH, Brennan L, Hertzberger R, Papkovsky D, Bourke B, Knaus UG. 2016. Defensive mutualism rescues NADPH oxidase inactivation in gut infection. Cell Host Microbe 19: 651-663. doi:10.1016/j.chom.2016.04.007

Robinson JT, Thorvaldsdóttir H, Winckler W, Guttman M, Lander ES, Getz G, Mesirov JP. 2011. Integrative genomics viewer. Nat Biotechnol 29: 24-26. doi:10.1038/nbt.1754

Schreiber S, Rosenstiel P, Albrecht M, Hampe J, Krawczak M. 2005. Genetics of Crohn disease, an archetypal inflammatory barrier disease. Nat Rev Genet 6: 376-388. doi:10.1038/nrg1607

Schwerd T, Bryant RV, Pandey S, Capitani M, Meran L, Cazier JB, Jung J, Mondal K, Parkes M, Mathew CG, et al. 2018. NOX1 loss-of-function genetic variants in patients with inflammatory bowel disease. Mucosal Immunol 11: 562-574. doi:10.1038/mi.2017.74

Shihab HA, Gough J, Cooper DN, Stenson PD, Barker GLA, Edwards KJ, Day INM, Gaunt TR. 2012. Predicting the functional, molecular, and phenotypic consequences of amino acid substitutions using hidden Markov models. Human Mutat 34: 57-65. doi:10.1002/humu.22225

Sommer F, Nookaew I, Sommer N, Fogelstrand P, Bäckhed F. 2015. Site-specific programming of the host epithelial transcriptome by the gut microbiota. Genome Biol 16. doi:10.1186/s13059-015-0614-4

Stasia MJ. 2016. CYBA encoding $\mathrm{p} 22^{\text {phox }}$, the cytochrome $b_{558}$ a polypeptide: gene structure, expression, role and physiopathology. Gene 586: 27-35. doi:10.1016/j.gene.2016.03.050

Suh YA, Arnold RS, Lassegue B, Shi J, Xu X, Sorescu D, Chung AB, Griendling KK, Lambeth JD. 1999. Cell transformation by the superoxide-generating oxidase Mox1. Nature 401: 79-82. doi:10.1038/43459

Taylor RM, Dratz EA, Jesaitis AJ. 2011. Invariant local conformation in $\mathrm{p} 22^{\text {phox }}$ p.Y72H polymorphisms suggested by mass spectral analysis of crosslinked human neutrophil flavocytochrome b. Biochimie 93: 1502-1509. doi:10.1016/j.biochi.2011.05.004

Uhlig HH. 2013. Monogenic diseases associated with intestinal inflammation: implications for the understanding of inflammatory bowel disease. Gut 62: 1795-1805. doi:10.1136/gutjnl-2012-303956

Uhlig HH, Schwerd T. 2016. From genes to mechanisms: the expanding spectrum of monogenic disorders associated with inflammatory bowel disease. Inflamm Bowel Dis 22: 202-212. doi:10.1097/MIB.000000000 0000614 
COLD SPRING HARBOR Molecular Case Studies
Nox1/CYBA missense variants in a veolBD patient

Uhlig HH, Schwerd T, Koletzko S, Shah N, Kammermeier J, Elkadri A, Ouahed J, Wilson DC, Travis SP, Turner $D$, et al. 2014. The diagnostic approach to monogenic very early onset inflammatory bowel disease. Gastroenterology 147: 990-1007.e3. doi:10.1053/j.gastro.2014.07.023

Waetzig GH, Seegert D, Rosenstiel P, Nikolaus S, Schreiber S. 2002. p38 mitogen-activated protein kinase is activated and linked to TNF-a signaling in inflammatory bowel disease. J Immunol 168: 5342-5351. doi:10.4049/jimmunol.168.10.5342

Wang K, Li M, Hakonarson H. 2010. ANNOVAR: functional annotation of genetic variants from high-throughput sequencing data. Nucleic Acids Res 38: e164. doi:10.1093/nar/gkq603

Warner N, Burberry A, Franchi L, Kim YG, McDonald C, Sartor MA, Núñez G. 2013. A genome-wide siRNA screen reveals positive and negative regulators of the NOD2 and NF-kB signaling pathways. Sci Signal 6: rs3. doi:10.1126/scisignal.2003305

Worthey EA, Mayer AN, Syverson GD, Helbling D, Bonacci BB, Decker B, Serpe JM, Dasu T, Tschannen MR, Veith RL, et al. 2011. Making a definitive diagnosis: successful clinical application of whole exome sequencing in a child with intractable inflammatory bowel disease. Genet Med 13: 255-262. doi:10.1097/ GIM.0b013e3182088158

Wyche KE, Wang SS, Griendling KK, Dikalov SI, Austin H, Rao S, Fink B, Harrison DG, Zafari AM. 2004. C242T CYBA polymorphism of the NADPH oxidase is associated with reduced respiratory burst in human neutrophils. Hypertension 43: 1246-1251. doi:10.1161/01.HYP.0000126579.50711.62

Yazdanpanah B, Wiegmann K, Tchikov V, Krut O, Pongratz C, Schramm M, Kleinridders A, Wunderlich T, Kashkar H, Utermöhlen O, et al. 2009. Riboflavin kinase couples TNF receptor 1 to NADPH oxidase. Nature 460: 1159-1163. doi:10.1038/nature08206

Zeissig Y, Petersen BS, Milutinovic S, Bosse E, Mayr G, Peuker K, Hartwig J, Keller A, Kohl M, Laass MW, et al. 2015. XIAP variants in male Crohn's disease. Gut 64: 66-76. doi:10.1136/gutjnl-2013-306520 


\section{COLD SPRING HARBOR Molecular Case Studies}

\section{Missense variants in NOX1 and p22phox in a case of very-early-onset inflammatory bowel disease are functionally linked to NOD2}

Simone Lipinski, Britt-Sabina Petersen, Matthias Barann, et al.

Cold Spring Harb Mol Case Stud 2019, 5: a002428

Access the most recent version at doi: $10.1101 /$ mcs.a002428
Supplementary http://molecularcasestudies.cshlp.org/content/suppl/2019/01/23/mcs.a002428.D Material C1
References This article cites 78 articles, 18 of which can be accessed free at: http://molecularcasestudies.cshlp.org/content/5/1/a002428.full.html\#ref-list-1
License This article is distributed under the terms of the Creative Commons Attribution-NonCommercial License, which permits reuse and redistribution, except for commercial purposes, provided that the original author and source are credited.
Email Alerting Receive free email alerts when new articles cite this article - sign up in the box at the Service top right corner of the article or click here.

